\title{
Rectal Prolapse
}

\author{
David P. O'Brien, IV, M.D.'
}

Despite the innovation of more than 100 surgical procedures for the treatment of complete rectal prolapse, no one procedure is best and applicable to all patients. Traditionally, procedures have been divided into abdominal and perineal approaches. The application of the laparoscopic approach to colon and rectal disease has allowed an additional less invasive method of therapy to treat rectal prolapse successfully. In comparison with conventional approaches, laparoscopy has achieved similar functional results and recurrence rates while reducing postoperative pain and hospital length of stay.

KEYWORDS: Rectal prolapse, laparoscopy, rectopexy, colon, rectum

Objectives: On completion of this article, the reader should be able to summarize the traditional and minimally invasive surgical options for treatment of rectal prolapse.

Rectal prolapse (or procidentia) is the description of full-thickness protrusion of all layers of rectum through the anal canal into the external environment. It is most common in young children and elderly people but can affect individuals at any age. It was described in Ebers Papyrus as early as $1500 \mathrm{BC}^{1}{ }^{1}$ Since that time, numerous methods of treatment have been proposed. These include both abdominal and perineal procedures. Various alterations in these procedures have been created in an attempt to optimize the repair. Despite the numerous descriptions, no one method has provided better results than all the others. In addition, few prospective data exist to guide our therapy. Initial strategies were developed in an attempt to restore normal anatomy. Unfortunately, merely restoring normal anatomy has not equated to success. An acceptable outcome can be achieved only by addressing the alterations in both function and anatomy. Although newer types of surgical procedures have yet to improve upon long-term results of traditional methods, the laparoscopic approach for rectal prolapse repair provides many potential benefits for the patient. Previous studies have demonstrated that the laparoscopic approach to colon and rectal surgery reduces pain, decreases wound infections, and shortens the length of hospital stay compared with conventional open operations. ${ }^{2}$ As with other laparoscopic procedures, there is the potential for a reduction in direct hospital costs. ${ }^{3}$ Notably, this technique must provide durable results with similar recurrence rates to those performed by traditional methods while maintaining a low morbidity rate.

\section{PATHOPHYSIOLOGY}

The precipitating factors in the development of complete rectal prolapse are not completely understood. Various theories have been put forth to explain the cause(s) of the prolapse. These include poor bowel habits, relaxation of the rectal suspensory ligaments, sliding herniation of a deep pouch of Douglas, and rectal wall intussusception. ${ }^{4}$ In 1968, Brodén and Snellman utilized cinedefecography to illustrate that rectal prolapse was in fact a fullthickness intussusception starting 8 to $10 \mathrm{~cm}$ above the dentate line and terminating beyond the anal verge. ${ }^{5}$

\footnotetext{
${ }^{1}$ Division of Colon and Rectal Surgery, Department of Surgery, University of Cincinnati College of Medicine, Cincinnati, Ohio. Address for correspondence and reprint requests: David P. O'Brien, IV, M.D., Division of Colon and Rectal Surgery, Department of Surgery, University of Cincinnati College of Medicine, 2123 Auburn Ave., Ste. 524, Cincinnati, OH 45219 (e-mail: obriendd@uc.edu).
}

Benign Anorectal Conditions; Guest Editor, Bradford Sklow, M.D. Clin Colon Rectal Surg 2007;20:125-132. Copyright (C) 2007 by Thieme Medical Publishers, Inc., 333 Seventh Avenue, New York, NY 10001, USA. Tel: +1(212) 584-4662.

DOI 10.1055/s-2007-977491. ISSN 1531-0043. 
Internal intussusception, defined as prolapse that does not project beyond the anal sphincter complex, is often demonstrated by defecography in otherwise normal patients without evidence of full-thickness rectal prolapse. Whether or not this internal intussusception represents an early finding in patients who eventually develop full-thickness prolapse is unclear. ${ }^{6}$ The inciting event may in fact be a result of a combination of factors related to functional disorders in the pelvic floor support mechanism, the abdominal wall musculature, and the anal sphincter complex. Numerous anatomic abnormalities are associated with rectal prolapse, and include an abnormally deep pouch of Douglas, lax and atonic muscles of the pelvic floor, weak anal sphincter muscles, nonrelaxing puborectalis, and poor sacral and lateral ligament fixation of the rectum. ${ }^{4,5,7}$

From a functional standpoint, 50 to $75 \%$ of patients with rectal prolapse exhibit fecal incontinence. ${ }^{4,8}$ This may be due to traumatic stretch injury to the sphincter complex, a finding that has been supported by endosonography. ${ }^{9-11}$ Alternatively, continuous stimulation of the rectoanal inhibitory reflex by the prolapse leads to chronic low internal anal sphincter pressures. ${ }^{12}$ This theory is supported by manometric studies comparing patients with fecal incontinence and rectal prolapse with patients with neurogenic fecal incontinence and with normal subjects that demonstrate the low resting pressures in patients with fecal incontinence and rectal prolapse. ${ }^{13}$ Fortunately, continence improves significantly after the repair of rectal prolapse, probably because of improvements in internal anal sphincter function. ${ }^{13-20}$

Constipation arising as either difficulty with evacuation or infrequent bowel movements occurs concomitantly with rectal prolapse in up to $72 \%$ of $\mathrm{pa}^{-}$ tients. ${ }^{21}$ However, the association between rectal prolapse and defecation disorders remains poorly understood. Most often constipation arises in the form of evacuation difficulty. ${ }^{21}$ This may be a result of an obstructing rectal intussusception or paradoxical puborectalis contraction. ${ }^{22,23}$ Slow-transit constipation may also be present and further complicate the disease process. Unfortunately, constipation can also complicate rectal prolapse repair. Suggested etiologies include rectal denervation from division of the lateral ligaments, ${ }^{24}$ kinking of the redundant loop of sigmoid colon at the junction between the sigmoid colon and the rectum, ${ }^{25}$ loss of rectal compliance as a result of mesh placement, ${ }^{26}$ and altered colonic motility. ${ }^{27}$ Avoiding the use of mesh and combining sigmoid colon resection with rectopexy could theoretically prevent this complication.

\section{CLINICAL EVALUATION}

Rectal prolapse can occur at any age but is more common in patients older than 50 . Women represent $\sim 90 \%$ of patients, with the peak incidence in the sixth decade of life. ${ }^{1}$ Although, multiparity has previously been suggested as an etiology for rectal prolapse, nulliparous women represent $\sim 40 \%$ of these patients. ${ }^{28}$ Patients with psychiatric disorders and those in nursing homes are often found to have this disease. Of individuals younger than 50 , up to $50 \%$ may harbor significant psychiatric disorders requiring chronic medical therapy. ${ }^{29}$

Patients are usually aware of the prolapsing rectum unless they are at the very extremes of age. The prolapse initially occurs while evacuating the rectum or while straining but reduces spontaneously. Eventually the prolapse becomes more chronic, requiring manual reduction and making even the simplest of daily activities difficult. Patients frequently complain of mucous drainage, bleeding, soilage, incontinence, and rarely pain. Women may complain of concomitant anterior pelvic organ prolapse. Examination of the perineum often reveals soilage with a patulous anus. Rectal tone is often poor or absent. Proctoscopy should be performed to rule out neoplasia as a cause of the prolapse. Colonoscopy (or barium enema) should be scheduled if not recently performed. If the prolapse is not readily appreciated in the prone-jackknife or left lateral decubitus position, the patient should be asked to strain on the toilet. The prolapse can be viewed by a placing a small telescoping mirror beneath the patient. Rectal prolapse must be differentiated from prolapsing internal hemorrhoids and from mucosal prolapse. The former is diagnosed when the folds of mucosa project in a radial fashion. In true rectal prolapse, the folds of mucosa are always concentric.

Theoretically, anal physiology testing including manometry and pudendal nerve terminal motor latency (PNTML) studies may be of value in some patients. Glasgow et al have suggested that patients with preoperative maximal squeeze pressures greater than $60 \mathrm{~mm}$ $\mathrm{Hg}$ have significantly improved outcomes with respect to continence after perineal proctectomy. ${ }^{30}$ However, postoperative continence has not been predicted by preoperative PNTML results. ${ }^{31,32}$ The results of these tests may not prevent one from proceeding with repair or alter the approach, but the information gained might provide prognostic information that is useful for both patient and physician. Others have suggested that clinical assessment of preoperative bowel function allows accurate selection of the appropriate technique for repair of prolapse without the added expense of anal physiologic testing. ${ }^{33}$ Further studies are needed to define the role (if any) for preoperative anal physiology testing in the evaluation of patients with rectal prolapse.

The presence of constipation can have a significant impact on the choice of operation for patients with rectal prolapse. A colonic transit study is essential to the evaluation of patients complaining of infrequent bowel movements or those requiring frequent laxative use. 
Patients with evidence of colonic inertia are candidates for total abdominal colectomy and ileorectal anastomosis at the time of prolapse repair.

\section{OPERATIVE REPAIR}

Unless extremely severe comorbidities exist, the treatment of rectal prolapse is surgical. There are numerous articles in the literature describing different operations for rectal prolapse. There are at least 130 different procedures that have been reported. Unfortunately, these reports are often retrospective and involve small numbers of patients. There are 11 randomized controlled trials evaluating procedures for rectal prolapse, and the largest involves only 63 patients. As a result, many areas of controversy remain. The procedures have been categorized as either abdominal or perineal. Traditionally, the perineal approach has been reserved for high-risk patients as surgeons have accepted the higher recurrence rates in exchange for lower morbidity. ${ }^{4}$ Proponents of the perineal approach argue that experienced surgeons can expect a recurrence rate of $\sim 9 \%$ with the perineal proctosigmoidectomy. ${ }^{34}$ Although this is higher than reported for abdominal repairs, it is considered an acceptable compromise for high-risk patients. The model procedure should repair the rectal prolapse, improve functional disorders including constipation and fecal incontinence, be minimally invasive, reduce costs, have low morbidity and mortality rates, and have a low recurrence rate. It has been demonstrated in prior studies that the minimally invasive laparoscopic approach to colon and rectal surgery reduces postoperative pain, decreases wound complications, shortens the length of hospital stay, and can reduce direct hospital costs. ${ }^{2,3}$ In surgery for rectal prolapse, laparoscopy has the potential benefits of allowing the surgeon to perform the same procedure that would be performed in the conventional open approach, thus preserving the low recurrence rates and yet maintaining the low morbidity rates seen in patients undergoing a perineal procedure.

\section{Traditional Procedures}

\section{PERINEAL REPAIRS}

Perineal procedures have the benefit of being able to be performed with local or regional anesthesia, or both, without the need for an abdominal incision. Although many operations have been described, the most common are the perineal proctosigmoidectomy (Altemeier operation) with or without levatorplasty and the Delorme procedure. Anal encirclement procedures including the Thiersch operation have all but been abandoned because of the high recurrence and local complication (infection, breakage, and erosion) rates. ${ }^{4}$
The perineal proctosigmoidectomy was introduced as a therapy for rectal prolapse over 100 years ago. Because of unacceptably high recurrence rates, this procedure had fallen out of favor until Altemeier et al reintroduced the procedure at the University of Cincinnati. They reported recurrence of rectal prolapse in 3 of the 106 patients undergoing the perineal approach. ${ }^{35}$ More recent series report rates of recurrence from 0 to $44 \%$ with most ranging from 0 to $16 \%{ }^{8,34}$ The primary benefit of this procedure is the extremely low complication rate. Anastomotic or pelvic bleeding, anastomotic leak, abscess, and stricture can all occur but at rates of $12 \%$ or less. ${ }^{34}$ In comparison with abdominal operations for prolapse, the perineal proctosigmoidectomy is not associated with sexual dysfunction in men. Studies evaluating sexual dysfunction after abdominal operations have reported the rates of retrograde ejaculation and impotence rates at $17 \% .{ }^{34}$ Finally, mortality rates for this procedure are low and range from 0 to $5 \%{ }^{8}$

Despite the loss of the rectum and potential reduction in anal sphincter function after perineal repair, ${ }^{36}$ most studies demonstrate improvement in continence similar to that of the abdominal repairs. ${ }^{4}$ The addition of the posterior levatorplasty has an additive effect to continence over perineal proctosigmoidectomy alone and also reduces short-term recurrence rates. ${ }^{37-40}$ Given all the preceding information, prospective randomized data comparing functional outcome of the perineal proctosigmoidectomy with abdominal repairs for rectal prolapse are lacking. Currently, the perineal proctosigmoidectomy combined with posterior levatorplasty remains an excellent choice for elderly patients and those with significant comorbidities. In addition, it is the procedure of choice for the incarcerated, strangulated, or gangrenous prolapsed rectum.

The Delorme procedure was first described by the French physician Edmond Delorme in $1900 .{ }^{41} \mathrm{It}$ is a less invasive operation most often utilized in cases of mucosal prolapse or short-segment full-thickness prolapse. In addition, it allows a perineal approach to prolapse repair associated with rectal ulceration or a large/circumferential polyp. ${ }^{42}$ In this operation, a circumferential incision is made across the mucosa $\sim 1 \mathrm{~cm}$ above the dentate line. Dissection is performed proximally in the submucosal plane above the prolapsed segment of rectum. The redundant mucosa is resected and the muscularis is plicated. A mucosa-to-mucosa anastomosis is then created. As with the perineal proctosigmoidectomy, this procedure is best suited for the surgical patient with significant comorbidities. It improves continence when performed with or without a concomitant sphincteroplasty. ${ }^{42,43}$ Tsunoda and colleagues demonstrated significant improvement in both anal resting and squeeze pressures associated with a $63 \%$ improvement in continence with the Delorme procedure alone in their series of 32 patients. ${ }^{43}$ Unfortunately, this procedure can be 
technically demanding and has a consistently higher recurrence rate $(0-38 \%)$ than perineal proctosigmoidectomy. 1,8

\section{ABDOMINAL REPAIRS}

A variety of abdominal approaches to repair rectal prolapse have been described, each with its own advantages and disadvantages. Operations including isolated sigmoid resection, anterior resection, transabdominal levator repair, and the cul-de-sac repair as described by Moschowitz have all been abandoned in favor of newer, more dependable techniques. ${ }^{4,8}$ The majority of current procedures involve rectal mobilization with suspension of the rectum out of the pelvis. Nevertheless, controversy remains about the extent of mobilization, the division of the lateral rectal ligaments, performance of concomitant sigmoid colon resection, and method of rectal fixation.

Mobilization of the rectum should extend posteriorly to the level of the levator ani muscles. Some authors also recommend anterior dissection to the upper third of the vagina. ${ }^{44}$ The role of division of the lateral ligaments has also been examined in several studies. Unfortunately, many of these are small retrospective studies involving different operations. Speakman et al compared lateral ligament division in a randomized controlled trial in 26 patients undergoing abdominal mesh rectopexy for rectal prolapse. ${ }^{24}$ Rectal prolapse recurred in 4 of the 12 patients in whom the lateral ligaments were preserved. When the lateral ligaments were divided no recurrences were observed, but 7 of the 14 patients suffered from significant postoperative constipation. Some have suggested that division of one ligament may serve as a reasonable compromise. ${ }^{7}$ Anal physiology testing performed on these patients suggests that ligament division is associated with decreased rectal pressure and reduced rectal compliance. ${ }^{45}$ These changes may account for at least some of the changes in postoperative anorectal function. Currently, preservation of the lateral ligaments appears to be the appropriate technique, given the acceptable rate of recurrence in studies in which the lateral ligaments are preserved and the high rate of constipation seen in patients with divided lateral ligaments.

Sigmoid colon resection combined with rectopexy was first described by Frykman and Goldberg in 1969 and has remained an excellent option for treatment of rectal prolapse. ${ }^{46}$ The addition of resection to the prolapse repair was intended to reduce recurrence as a result of suspension of the left colon from the splenic flexure. Although this procedure has not further reduced recurrence, it has improved the rate of postoperative constipation. Two randomized controlled trials have demonstrated a significant reduction in postoperative constipation in patients having sigmoid colon resection in addition to rectopexy when compared with patients undergoing rectopexy alone. ${ }^{25,47}$ McKee et al demon- strated a significant increase in retention of colonic transit markers in patients not having sigmoid resection. One of the five patients in the Luukkonen et al study who developed constipation after rectopexy alone ultimately required a colectomy. The performance of combined sigmoid colon resection and rectopexy does not ensure lack of postoperative constipation. Those with a significant history of constipation should have a colonic transit study performed preoperatively. Consideration should be given to a total abdominal colectomy and suture rectopexy for those with retention of colonic transit markers scattered throughout the colon. Unfortunately, fecal incontinence may complicate the recovery of patients with combined rectal prolapse, slow-transit constipation, and a weak anal sphincter mechanism. ${ }^{7}$

Once mobilized, the rectum is secured outside the pelvis. Fixation to the presacral fascia may be performed with or without mesh. The method chosen must best prevent recurrence without significantly increasing postoperative difficulties with evacuation or rates of infection. Ripstein described an anterior repair in which mesh is draped across the anterior aspect of the rectum at the level of the peritoneal reflection and secured to the sacrum. ${ }^{48}$ Because of concern about stenosis, obstruction, and mesh erosion into the rectum, fixation techniques evolved to eliminate the anterior component of the repair. ${ }^{49}$ In the repair described by Wells, mesh is secured to the sacrum and then fixed to the lateral mesorectum. ${ }^{50}$ Both the Wells and Ripstein repairs are extremely successful, with recurrence rates less than $10 \%{ }^{4,8}$ Postoperative constipation rates vary significantly from study to study with little consistency. ${ }^{8}$ Alternatively, the Orr-Loygue rectopexy utilizes mesh strips that are attached to the anterolateral rectum and secured to the sacral promontory. ${ }^{51}$ Recurrence rates are low, but significant postoperative evacuation difficulties have been described. ${ }^{51}$ Although the polyvinyl alcohol sponge (Ivalon sponge) was used in the original description of the Wells procedure, most surgeons today use a variety of alternative mesh types. This is due to the increased rates of infection demonstrated in studies utilizing the polyvinyl alcohol sponge. ${ }^{52,53}$ The author prefers polypropylene but recognizes that there is no evidence to support its superiority over any others mesh types or suture rectopexy alone. ${ }^{54}$ There is a theoretical advantage of suture rectopexy over the repairs utilizing mesh. The lack of mesh could provide a reduction in the rates of postoperative infection and constipation. It is also ideal for combined resection rectopexy procedures where the potential for spillage exists. However, the recurrence rates are no different from those with mesh repairs, and there is no evidence to suggest that the rates of postoperative constipation are improved as a result of mesh omission. ${ }^{8}$ Currently, there are no prospective data to support clearly the performance of one repair over any other. 


\section{Laparoscopic Procedures}

The application of laparoscopic surgery to diseases of the colon and rectum has resulted in reduced postoperative pain, decreased wound infections, and a shortened hospital stay. ${ }^{2}$ Although it is too often considered unimportant, there is an obvious improvement in cosmesis. The laparoscopic repair of rectal prolapse has demonstrated many of the same benefits. Unfortunately, most of the studies performed to date are small and retrospective. The existing prospective studies comparing laparoscopic treatment of rectal prolapse with the conventional abdominal approach favor laparoscopy. ${ }^{55,56}$ Boccasanta et al compared the functional and clinical results of 23 patients undergoing laparoscopic or open Wells procedure for rectal prolapse. ${ }^{55}$ In both groups, there was an equal and significant improvement in dyschezia and fecal incontinence. The hospital stay was shorter and less costly in the laparoscopic group. In 2002, Solomon et al randomly assigned 39 patients to either laparoscopic or open mesh rectopexy. ${ }^{56}$ Patients in the laparoscopic group had significantly less pain and less morbidity and were discharged from the hospital earlier. There were similar improvements in incontinence rates, and there was no significant increase in constipation in either the laparoscopic or open group. Purkayastha et al published a meta-analysis comparing laparoscopic and open abdominal procedures to treat full-thickness rectal prolapse. ${ }^{57}$ Primary and secondary endpoints included postoperative morbidity, recurrence, operative time, and hospital length of stay. The analysis included six studies involving a total of 195 patients (97 laparoscopic and 98 open). Follow-up ranged from 12 to 37 months. There were no significant differences in morbidity or recurrence, operative time was longer and length of stay was shorter in the laparoscopic group. There were no meaningful conclusions that could be drawn about the rates of constipation and fecal incontinence. Notably, two of the studies included in the meta-analysis compared costs. ${ }^{55,58}$ Although both studies concluded that the expense of the operative materials was higher for laparoscopy, the mean overall costs were significantly lower in the laparoscopic groups.

The benefit of the laparoscopic approach is that the same operation that is performed through a large abdominal incision can be performed through multiple small incisions. The largest is often a $12-\mathrm{mm}$ infraumbilical camera trocar incision. With the advent of $5-\mathrm{mm}$ cameras, suture rectopexy without concomitant sigmoid colon resection can be performed through four $5-\mathrm{mm}$ incisions. For resection rectopexy procedures, the sigmoid colon can be extracted through a small incision placed either in the left lower quadrant or through a Pfannenstiel incision placed $2-\mathrm{cm}$ above the pubic symphysis. Patients should be positioned in the lithotomy position or on a leg splitting table secured by a bean bag. The presacral space is entered just as it would be in the open procedure. Dissection is carried posteriorly in the midline to the levator ani muscles. The lateral ligaments are preserved. Anterior dissection in the rectovaginal septum may be performed if desired. In the performance of the Wells procedure, mesh is secured to the sacral promontory and then the lateral mesorectum is sutured to the mesh, suspending the rectum out of the pelvis. In the case of suture rectopexy, the lateral mesorectum is secured directly to the presacral fascia or periosteum. During resection rectopexy the specimen may be removed through the left lower quadrant incision after endoscopic transection or transection may be performed after extraction through the Pfannenstiel incision. A double-stapled anastomosis can be completed after closure of the incisions or under direct vision in the case of the Pfannenstiel incision. The author prefers the Pfannenstiel incision because suture rectopexy is easier to perform through the incision than laparoscopically and any anastomotic leaks identified can be directly repaired.

\section{MANAGEMENT OF RECURRENT RECTAL PROLAPSE}

The recurrence rates following repair of rectal prolapse have been reported to be as high as $29 \%$ and vary greatly between series and institutions. ${ }^{59}$ Recurrences tend to occur early after repair, with a mean interval of 24 to 44 months in larger series and close to one third occurring in the first 7 months. ${ }^{59-61}$ Recurrence has occurred up to 14 years after initial repair. ${ }^{61}$ Although the results of some studies suggest equivalent rates of recurrence between abdominal and perineal approaches to prolapse repair, the majority demonstrate higher rates of recurrence for the perineal approach. ${ }^{4}$ The cause of recurrent rectal prolapse is difficult to determine but often thought to be technical. ${ }^{60,61}$ Late recurrences suggest that alternative mechanisms, including inherent patient-related factors, may play a role.

All of the studies examining recurrent rectal prolapse are retrospective and suffer from relatively short follow-up periods. Thus, management of this difficult problem suffers from a lack of effective data to guide therapy. However, there are a few conclusions that can be drawn. The outcome of a second repair can be just as successful as the initial repair with a low recurrence rate. ${ }^{61,62}$ From a functional standpoint, there seems to be no significant change or improvement in either fecal incontinence or constipation. ${ }^{60,62}$

As part of the evaluation of the patient with recurrent rectal prolapse, one must investigate any factors that may have contributed to the recurrence. This would include both patient-related factors including slow-transit constipation and nonrelaxing puborectalis and any technical aspects of the original operation that may have contributed to a failed repair. ${ }^{63}$ Any procedure involving a second resection should consider removing 
the prior anastomosis. If not, ischemia and stricture may ensue. Consideration should be given to preserving the superior hemorrhoidal artery in cases of abdominal resection rectopexy following a perineal proctosigmoidectomy as it may reduce the rates of stricture formation. ${ }^{61}$ Steele et al reported on a total of 78 patients undergoing repair of a recurrent rectal prolapse in the Department of Colorectal Surgery at the University of Minnesota. ${ }^{61}$ Successful repair was reported in $85 \%$ of patients undergoing an abdominal approach versus 63\% of patients undergoing perineal procedures. In patients requiring a third repair, the abdominal approach was again the more successful procedure no matter how the prior two procedures were performed.

The data on laparoscopy for the management of recurrent rectal prolapse are extremely limited. Tsugawa et al reported on two cases of recurrent rectal prolapse managed successfully by laparoscopic suture rectopexy. ${ }^{64}$ No complications or recurrences were noted at 24 months. Delaney and Senagore also recommended laparoscopy after failed perineal proctosigmoidectomy. ${ }^{63}$

In summary, limited data exist to provide guidelines on the management of recurrent rectal prolapse. However, the abdominal approach is associated with a lower recurrence rate no matter the number of prior repairs and should be the procedure of choice. Experienced surgeons may elect to utilize laparoscopy for those with a failed perineal procedure.

\section{CONCLUSION}

Rectal prolapse is common problem evaluated and treated by the colon and rectal surgeon. More thorough evaluation of both anatomy and function has allowed a better choice of operation. Despite the large number of operations developed, no one operation consistently provides better results for all patients. In addition, few prospective data exist to guide therapy. Perineal procedures are best reserved for patients with significant comorbidities or patients with incarceration, strangulation, or gangrenous prolapsed rectum. The perineal proctosigmoidectomy is easier to perform than the Delorme procedure and has a lower recurrence rate. Posterior levatorplasty should be included as it has an additive effect on postoperative continence rates. $\mathrm{Pa}$ tients of acceptable risk should undergo an abdominal repair. When a history of infrequent bowel movements or need for laxatives is given, patients should undergo a colonic transit study to evaluate for slow-transit constipation. Patients with this disease should be considered for total abdominal colectomy with ileorectal anastomosis and suture rectopexy. Those without slow-transit constipation deserve sigmoid colon resection and suture rectopexy. Patients without symptoms of constipation are candidates for rectopexy alone with or without mesh. Experienced minimally invasive colon and rectal surgeons may choose to perform these procedures laparoscopically. Current data suggest that laparoscopic repair of rectal prolapse results in equal or improved morbidity rates, shorter hospital length of stay, and reduced hospital costs compared with the open approach. The role of laparoscopy in the management of recurrent rectal prolapse has yet to be defined. Additional larger prospective randomized studies are needed to delineate further the role of perineal, abdominal, and laparoscopic operations in the management of patients with rectal prolapse.

\section{REFERENCES}

1. Corman ML. Rectal prolapse, solitary rectal ulcer, syndrome of the descending perineum, and rectocele. Colon and Rectal Surgery. 5th ed. Philadelphia, PA: Lippincott Williams \& Wilkins; 2004:1408

2. Schwenk W, Haase O, Neudecker J, Muller JM. Short term benefits for laparoscopic colorectal resection. Cochrane Database Syst Rev 2005;(2):CD003145

3. Delaney CP, Kiran RP, Senagore AJ, Brady K, Fazio VW. Case-matched comparison of clinical and financial outcome after laparoscopic or open colorectal surgery. Ann Surg 2003; 238:67-72

4. Madoff $\mathrm{RD}$, Mellgren A. One hundred years of rectal prolapse surgery. Dis Colon Rectum 1999;42:441-450

5. Broden B, Snellman B. Procidentia of the rectum studied with cineradiography. A contribution to the discussion of causative mechanism. Dis Colon Rectum 1968;11:330-347

6. Shorvon PJ, McHugh S, Diamant NE, Somers S, Stevenson GW. Defecography in normal volunteers: results and implications. Gut 1989;30:1737-1749

7. Hull TL. Rectal prolapse: abdominal approach. Clin Colon Rectal Surg 2003;16:259-262

8. Madiba TE, Baig MK, Wexner SD. Surgical management of rectal prolapse. Arch Surg 2005;140:63-73

9. Halligan S, Sultan A, Rottenberg G, Bartram CI. Endosonography of the anal sphincters in solitary rectal ulcer syndrome. Int J Colorectal Dis 1995;10:79-82

10. Woods R, Voyvodic F, Schloithe AC, Sage MR, Wattchow DA. Anal sphincter tears in patients with rectal prolapse and faecal incontinence. Colorectal Dis 2003;5:544-548

11. Dvorkin LS, Chan CL, Knowles CH, et al. Anal sphincter morphology in patients with full-thickness rectal prolapse. Dis Colon Rectum 2004;47:198-203

12. Spencer RJ. Manometric studies in rectal prolapse. Dis Colon Rectum 1984;27:523-525

13. Farouk R, Duthie GS, MacGregor AB, Bartolo DC Rectoanal inhibition and incontinence in patients with rectal prolapse. Br J Surg 1994;81:743-746

14. Broden G, Dolk A, Holmstrom B. Recovery of the internal anal sphincter following rectopexy: a possible explanation for continence improvement. Int J Colorectal Dis 1988;3:23-28

15. Williams JG, Wong WD, Jensen L, Rothenberger DA, Goldberg SM. Incontinence and rectal prolapse: a prospective manometric study. Dis Colon Rectum 1991;34:209-216

16. Sainio AP, Voutilainen PE, Husa AI. Recovery of anal sphincter function following transabdominal repair of rectal prolapse: cause of improved continence? Dis Colon Rectum 1991;34:816-821 
17. Hiltunen KM, Matikainen M. Improvement of continence after abdominal rectopexy for rectal prolapse. Int J Colorectal Dis $1992 ; 7: 8-10$

18. Farouk R, Duthie GS, Bartolo DC, MacGregor AB. Restoration of continence following rectopexy for rectal prolapse and recovery of the internal anal sphincter electromyogram. Br J Surg 1992;79:439-440

19. Schultz I, Mellgren A, Dolk A, Johansson C, Holmstrom B. Continence is improved after the Ripstein rectopexy. Different mechanisms in rectal prolapse and rectal intussusception? Dis Colon Rectum 1996;39:300-306

20. Poen AC, de Brauw M, Felt-Bersma RJ, de Jong D, Cuesta MA. Laparoscopic rectopexy for complete rectal prolapse. Clinical outcome and anorectal function tests. Surg Endosc 1996;10:904-908

21. Kairaluoma MV, Kellokumpu IH. Epidemiologic aspects of complete rectal prolapse. Scand J Surg 2005;94:207-210

22. Womack NR, Williams NS, Holmfield JH, Morrison JF. Pressure and prolapse - the cause of solitary rectal ulceration. Gut 1987;28:1228-1233

23. Agachan F, Pfeifer J, Wexner SD. Defecography and proctography. Results of 744 patients. Dis Colon Rectum 1996;39:899-905

24. Speakman CT, Madden MV, Nicholls RJ, Kamm MA Lateral ligament division during rectopexy causes constipation but prevents recurrence: results of a prospective randomized study. Br J Surg 1991;78:1431-1433

25. McKee RF, Lauder JC, Poon FW, Aitchison MA, Finlay IG. A prospective randomized study of abdominal rectopexy with and without sigmoidectomy in rectal prolapse. Surg Gynecol Obstet 1992;174:145-148

26. Allen-Mersh TG, Turner MJ, Mann CV. Effect of abdominal Ivalon rectopexy on bowel habit and rectal wall. Dis Colon Rectum 1990;33:550-553

27. Siproudhis L, Ropert A, Gosselin A, et al. Constipation after rectopexy for rectal prolapse. Where is the obstruction? Dig Dis Sci 1993;38:1801-1808

28. Wassef R, Rothenberger DA, Goldberg SM. Rectal prolapse. Curr Probl Surg 1986;23:397-451

29. Marceau C, Parc Y, Debroux E, Tiret E, Parc R. Complete rectal prolapse in young patients: psychiatric disease a risk factor of poor outcome. Colorectal Dis 2005;7:360365

30. Glasgow SC, Birnbaum EH, Kodner IJ, Fleshman JW, Dietz DW. Preoperative anal manometry predicts continence after perineal proctectomy for rectal prolapse. Dis Colon Rectum 2006;49:1052-1058

31. Schultz I, Mellgren A, Nilsson BY, Dolk A, Holmstrom B. Preoperative electrophysiologic assessment cannot predict continence after rectopexy. Dis Colon Rectum 1998;41: $1392-1398$

32. Johansen OB, Wexner SD, Daniel N, Nogueras JJ, Jagelman DG. Perineal rectosigmoidectomy in the elderly. Dis Colon Rectum 1993;36:767-772

33. Madbouly KM, Senagore AJ, Delaney CP, et al. Clinically based management of rectal prolapse. Surg Endosc 2003;17: 99-103

34. Gregorcyk SG. Perineal proctosigmoidectomy: the procedure of choice for rectal prolapse. Clin Colon Rectal Surg 2003;16:263-269

35. Altemeier WA, Culbertson WR, Schowengerdt C, Hunt J. Nineteen years' experience with the one-stage perineal repair of rectal prolapse. Ann Surg 1971;173:993-1006
36. Deen KI, Grant E, Billingham C, Keighley MR. Abdominal resection rectopexy with pelvic floor repair versus perineal rectosigmoidectomy and pelvic floor repair for full-thickness rectal prolapse. Br J Surg 1994;81:302-304

37. Williams JG, Rothenberger DA, Madoff RD, Goldberg SM. Treatment of rectal prolapse in the elderly by perineal rectosigmoidectomy. Dis Colon Rectum 1992;35:830-834

38. Agachan F, Reissman P, Pfeifer J, et al. Comparison of three perineal procedures for the treatment of rectal prolapse. South Med J 1997;90:925-932

39. Kohler A, Athanasiadis S. The value of posterior levator repair in the treatment of anorectal incontinence due to rectal prolapse - a clinical and manometric study. Langenbecks Arch Surg 2001;386:188-192

40. Chun SW, Pikarsky AJ, You SY, et al. Perineal rectosigmoidectomy for rectal prolapse: role of levatorplasty. Tech Coloproctol 2004;8:3-8; discussion 8-9

41. Classic articles in colonic and rectal surgery. Edmond Delorme 1847-1929. On the treatment of total prolapse of the rectum by excision of the rectal mucous membranes or recto-colic. Dis Colon Rectum 1985;28:544-553

42. Pescatori M, Interisano A, Stolfi VM, Zoffoli M. Delorme's operation and sphincteroplasty for rectal prolapse and fecal incontinence. Int J Colorectal Dis 1998;13:223-227

43. Tsunoda A, Yasuda N, Yokoyama N, Kamiyama G, Kusano M. Delorme's procedure for rectal prolapse: clinical and physiological analysis. Dis Colon Rectum 2003;46:12601265

44. Felt-Bersma RJ, Cuesta MA. Rectal prolapse, rectal intussusception, rectocele, and solitary rectal ulcer syndrome. Gastroenterol Clin North Am 2001;30:199-222

45. Mollen RM, Kuijpers JH, van Hoek F. Effects of rectal mobilization and lateral ligaments division on colonic and anorectal function. Dis Colon Rectum 2000;43:12831287

46. Frykman HM, Goldberg SM. The surgical treatment of rectal procidentia. Surg Gynecol Obstet 1969;129:1225-1230

47. Luukkonen P, Mikkonen U, Jarvinen H. Abdominal rectopexy with sigmoidectomy vs. rectopexy alone for rectal prolapse: a prospective, randomized study. Int J Colorectal Dis 1992;7:219-222

48. Ripstein CB. Surgical care of massive rectal prolapse. Dis Colon Rectum 1965;8:34-38

49. Gordon PH, Hoexter B. Complications of the Ripstein procedure. Dis Colon Rectum 1978;21:277-280

50. Wells C. New operation for rectal prolapse. Proc R Soc Med 1959;52:602-603

51. Douard R, Frileux P, Brunel M, et al. Functional results after the Orr-Loygue transabdominal rectopexy for complete rectal prolapse. Dis Colon Rectum 2003;46:1089-1096

52. Ross AH, Thomson JP. Management of infection after prosthetic abdominal rectopexy (Wells' procedure). Br J Surg 1989;76:610-612

53. Athanasiadis S, Weyand G, Heiligers J, Heumuller L, Barthelmes L. The risk of infection of three synthetic materials used in rectopexy with or without colonic resection for rectal prolapse. Int J Colorectal Dis 1996;11:42-44

54. Bachoo P, Brazzelli M, Grant A. Surgery for complete rectal prolapse in adults. Cochrane Database of Systematic Reviews (Online) 2000;(2):CD001758

55. Boccasanta P, Venturi M, Reitano MC, et al. Laparotomic vs. laparoscopic rectopexy in complete rectal prolapse. Dig Surg 1999;16:415-419 
56. Solomon MJ, Young CJ, Eyers AA, Roberts RA. Randomized clinical trial of laparoscopic versus open abdominal rectopexy for rectal prolapse. Br J Surg 2002; 89:35-39

57. Purkayastha S, Tekkis $\mathrm{P}$, Athanasiou T, et al. A comparison of open vs. laparoscopic abdominal rectopexy for fullthickness rectal prolapse: a meta-analysis. Dis Colon Rectum 2005;48:1930-1940

58. Salkeld G, Bagia M, Solomon M. Economic impact of laparoscopic versus open abdominal rectopexy. Br J Surg 2004;91:1188-1191

59. Raftopoulos Y, Senagore AJ, Di Giuro G, Bergamaschi R. Recurrence rates after abdominal surgery for complete rectal prolapse: a multicenter pooled analysis of 643 individual patient data. Dis Colon Rectum 2005;48: 1200-1206
60. Hool GR, Hull TL, Fazio VW. Surgical treatment of recurrent complete rectal prolapse: a thirty-year experience. Dis Colon Rectum 1997;40:270-272

61. Steele SR, Goetz LH, Minami S, et al. Management of recurrent rectal prolapse: surgical approach influences outcome. Dis Colon Rectum 2006;49:440-445

62. Pikarsky AJ, Joo JS, Wexner SD, et al. Recurrent rectal prolapse: what is the next good option? Dis Colon Rectum 2000;43:1273-1276

63. Delaney CP, Senagore AJ. Current Therapy in Colon and Rectal Surgery. 2nd ed. Philadelphia, PA: Elsevier Mosby; 2005:624

64. Tsugawa K, Sue K, Koyanagi N, et al. Laparoscopic rectopexy for recurrent rectal prolapse: a safe and simple procedure without a mesh prosthesis. Hepatogastroenterology 2002;49:1549-1551 